Recepción: 16 / 04 / 2018

Aceptación: 09 / 06 / 2018

Publicación: 02 / 07 / 2018

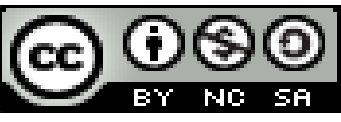

Ciencias técnicas y aplicadas

Artículo de investigación

\title{
Elaboración, caracterización y posibles aplicaciones de briquetas de residuos de café (borra) como biocombustible sólido
}
Elaboration, characterization and possible applications of briquettes of coffee residues (borra) as a solid biofuel

\section{Elaboração, caracterização e possíveis aplicações de briquetes de resíduos de café (borra) como biocombustível sólido}

Otto F. Balseca-Sampedro ${ }^{\mathrm{I}}$ ottobalsecaec@hotmail.com

Santiago A. López-Ortiz ${ }^{\text {II }}$ santilo86@hotmail.com

Edwin F. Viteri-Núñez ${ }^{\text {III }}$ eviteri@espoch.edu.ec

Darwin S. Analuisa-Lopez ${ }^{\text {IV }}$

darwingsa@hotmail.com

Edison V. Hernandez-Gavilanes ${ }^{\mathrm{V}}$ edi_hernandez1608@hotmail.com

Correspondencia: ottobalsecaec@ hotmail.com

\footnotetext{
I Magister en sistemas de Transporte de Petróleo y Derivados, Ingeniero Mecánico, Docente en la Escuela Superior Politécnica de Chimborazo, Riobamba, Ecuador.

${ }^{\text {II }}$ Magister en Diseño Mecánico, Ingeniero Mecánico, Docente de la Escuela Superior Politécnica de Chimborazo, Riobamba, Ecuador.

III Magister en Gerencia de Proyectos de Ecoturismo, Ingeniero Mecánico, Docente en la Escuela Superior Politécnica de Chimborazo, Riobamba, Ecuador.

${ }^{\text {Iv }}$ Magister en Seguridad Industrial y Salud Ocupacional, Ingeniero en Industrias Pecuarias, Docente en la Escuela Superior Politécnica de Chimborazo, Riobamba, Ecuador.

v Maestro en Ingeniería Automotriz, Ingeniero Automotriz, Docente en la Escuela Superior Politécnica de Chimborazo, Riobamba, Ecuador.
} 


\section{Resumen}

El presente trabajo basado en el área energética tiene como objetivo la elaboración de briquetas de residuos de café (borra), con el fin de verificar si este producto es considerado como biocombustible mediante la determinación de su poder calorífico establecido en la norma NTC2060, este producto pueden ser una gran oportunidad para producir energía calorífica a partir de biomasa procedente de residuos agroindustriales. Para la producción de briquetas se implementó el diseño y construcción de una prensa briquetadora, la cual ayudo a compactar los residuos de café, el ensayo de poder calorífico se desarrolló mediante la bomba calorimétrica y por el método de la ecuación de la energía de los alimentos aplicando un análisis bromatológico, igualmente se realizó el estudio de las características químicas, energéticas y físicas de las briquetas pertenecientes a la caracterización de la biomasa. Además, se realizan pruebas de incineración tanto a las briquetas como al carbón vegetal consiguiendo datos de temperatura y tiempo de duración cuando están encendidas tipo llama y brasa, finalmente se compara el poder calorífico de la briqueta de residuos de café con otros biocombustibles sólidos para verificar si estas briquetas son un posible sustituto de estos en ciertas aplicaciones como: calefacción, asaderos, hervir agua, generación de vapor, saunas húmedos y secos, etc.

Palabras clave: Poder calorífico; residuos de café (Borra); biocombustible; briquetas; biomasa.

\section{Abstract}

The present work based on the energy area has the objective of preparing briquettes of coffee residues (borra), to verify if this product is considered as biofuel by determining its calorific value established in the NTC-2060 standard, this product can be a great opportunity to produce heat energy from biomass from agroindustry waste. To produce briquettes, the design and construction of a briquette press was implemented, which helped to compact the coffee residues, the calorific power test was developed by the calorimetric pump and by the energy equation method of the food. applying a bromatological analysis, the study of the chemical, energetic and physical characteristics of the briquettes belonging to the characterization of the biomass was also carried out. In addition, incineration tests are carried out on both briquettes and charcoal obtaining temperature data and duration time when they are lit type flame and embers, finally the calorific value of the coffee waste briquette is compared with other solid biofuels to verify if 
these briquettes are a possible substitute for these in certain applications such as: heating, grills, boiling water, steam generation, wet and dry sauna, etc.

Keywords: Heat power; residue of coffee (lees); biofuel; briquettes; biomass.

\section{Resumo}

O presente trabalho com base no sector da energia tem como objectivo tornar resíduo briquetes café (excluído), a fim de verificar se este produto é considerado como biocombustível por determinação do seu poder calorífico estabelecido na norma ISO-2060, este produto pode ser uma ótima oportunidade para produzir energia térmica a partir de biomassa a partir de resíduos agroindustriais. Para a produção de briquetes de concepção e construção de uma imprensa briquete é implementado que ajudou a compactação do calorífico ensaio café resíduo desenvolvido por calorimetria bomba eo método de alimentos equação de energia aplicação de uma análise de composição química, também foi realizado o estudo de energia química, e as características físicas dos briquetes pertencentes à caracterização da biomassa. Além disso, queimaduras do teste são realizados ambos os briquetes de carvão vegetal como a obtenção de dados de temperatura e tempo de duração quando iluminada tipo de chama e brasa, finalmente, o valor calorífico dos resíduos de café briquete em comparação com outros biocombustíveis sólidos para verificar Se estes briquetes são um substituto possível em certas aplicações tais como aquecimento, churrasco, água a ferver, a geração de vapor, saunas molhado e seco, etc.

Palavras chave: resíduos de café caloríficos (Borra); biocombustível; briquetes; biomassa.

\section{Introducción}

Algunos materiales procedentes de fuentes renovables como residuos vegetales se están convirtiendo en una alternativa prometedora para la generación de la llamada bioenergía para reemplazar al menos alguna parte de los combustibles fósiles y no renovables como el carbón, el petróleo, entre otros ya que estos se han convertidos en una preocupación ambiental importante debido al hecho de que son potencialmente contaminantes. (HU J, Ley, T. et al, 2014) (Silva, 2007) 
El uso de briquetas orgánicas, principalmente en la industria, se revitalizó durante el período de altos precios de la energía en los años 70 y principios de los años 80, especialmente en Escandinavia, los EE.UU. y Canadá. (FAO, 2012)

La briqueta producida a partir de biomasa vegetal es una fuente de energía que se puede obtener con baja tecnología y bajo nivel de inversión, a nivel mundial en el año 2012 los datos de producción y comercio de briquetas de madera fueron de 19 y 9 millones de toneladas respectivamente. Europa y América del Norte mantienen casi toda la producción mundial (66 \% y $31 \%$ respectivamente), y el consumo (80\% y $17 \%$ respectivamente). (FAO, 2012)

En América Latina, según estimaciones basadas en datos de la ONU, 23\% de la población de esta región depende todavía del uso de la leña como fuente de energía, esto representa que anualmente se consumen 66 millones de toneladas de leña para cocción y calefacción, además no se encuentran datos específicos de consumo y producción de briquetas. (FAO, 2012)

En cuanto a la producción de pellets y briquetas en Ecuador el estudio realizado por Pelaez y Espinoza (2015), los primeros análisis del briquetado se dieron a mitad del año 1980 en la provincia del Guayas, con el fin de vender briquetas a los ingenios azucareros; sin embargo, el proyecto no prosperó dado el bajo precio de los combustibles y problemas con la higroscopicidad de las briquetas producidas. Nuevamente, la escasa atención dada a combustibles alternativos y los bajos precios de los combustibles desincentivaron la continuación de estos estudios.

Actualmente, el Instituto Nacional de Eficiencia Energética y Energías Renovables (INER), trabaja en la obtención de un pellet que cumpla con los estándares de la normativa BSEN-14961. Algunos de los estándares que se busca cumplir mediante el pre tratamiento y posterior pelletizado son: poder calórico, contenido de humedad, durabilidad mecánica, diámetro, longitud, cenizas, nitrógeno, azufre y cloro. (Instituto Nacional de Eficiencia Energética y Energías Renovables, (INER). 2016)

Las briquetas se hacen de materiales sólidos, generalmente en forma de pequeñas partículas o polvos que se presiona en prensas hidráulicas o mecánicas con el fin de obtener un material compactado generalmente en la forma de pequeños cilindros o discos para ser utilizados como combustibles. (Filippeto, 2008) 
En cuanto a la existencia de máquinas o prensas briquetadoras se encuentran varios tipos como las máquinas artesanales, semi industriales y las industriales; las máquinas artesanales utilizan siempre algún tipo de aglutinante y la presión de compactación varía entre 0,5-2,6 MPa., (Janczack, J. 1981), igualmente en las máquinas semi industriales se utiliza menor cantidad de aglutinante la presión de compactación varía entre 5-100 MPa. (Mandruga, E. 1981), y en el proceso industrial las máquinas briquetadoras no utilizan ningún tipo de aglutinante debido que en este proceso se fabrican las briquetas con altas temperaturas $\left(165^{\circ} \mathrm{C}\right)$ y presiones mayores a $100 \mathrm{MPa}$. (Mandruga, E. 1981)

\section{Materiales y métodos}

Dentro de los materiales y métodos para la elaboración, caracterización y posibles aplicaciones de briquetas de residuos de café se encuentran: la presión de compactación y mezcla adecuada entre los residuos de café, aglutinante y agua, el diseño y la construcción de la máquina o prensa briquetadora.

\section{A. Determinación de la mezcla y parámetros adecuados para la elaboración de las briquetas}

La presión de compactación y mezcla adecuada que permite obtener una briqueta cilíndrica maciza y de fácil expulsión del molde se obtuvo mediante el ensayo de compactación realizada en la Máquina Universal de la Facultad de Mecánica de la Escuela Superior Politécnica de Chimborazo datos que se muestra en la tabla 1.

Tabla 1. Composición de la mezcla y parámetros

\begin{tabular}{|l|c|}
\hline \multicolumn{1}{|c|}{ Sustancio y/o parámetros } & Datos \\
\hline Residuos de café (borra) & $11 / 2 \mathrm{lb}(72,68 \%)$ \\
\hline Aglutinante (almidón de yuca) & $200 \mathrm{~g} \mathrm{(12,82 \% )}$ \\
\hline Agua & $40 \mathrm{ml}(14,5 \%)$ \\
\hline Presión & $2,77 \mathrm{MPa}$ \\
\hline Altura de la briqueta & $50 \mathrm{~mm}$ \\
\hline Diámetro de la briqueta & $47 \mathrm{~mm}$ \\
\hline
\end{tabular}

El aglutinante seleccionado es el almidón de yuca debido a que tiene mayor viscosidad que otros cultivos y no produce mucha contaminación cuando se combustiona (FAO, 2006) 


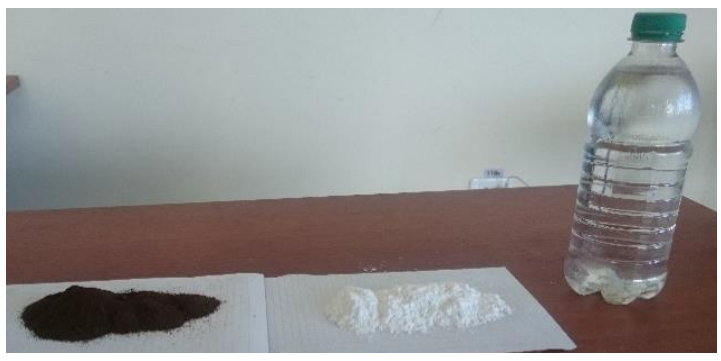

Figura 1. Sustancias de la mezcla adecuada para elaborar briquetas de residuos de café.

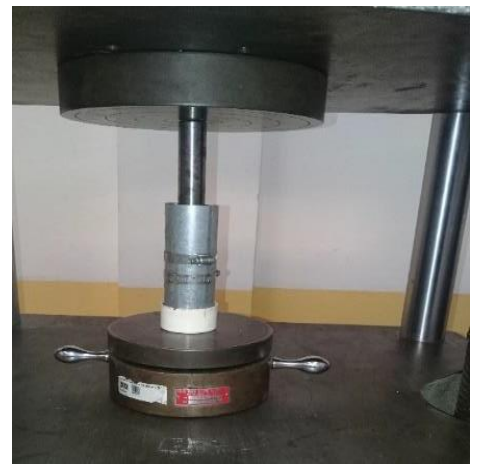

Figura 2. Ensayo de compactación en la maquina universal

\section{B. Diseño de la máquina o prensa briquetadora.}

Para realizar el diseño de la máquina briquetadora se orientará en el ciclo básico de diseño el mismo que es una forma particular del método de resolución de problemas cuyas actividades se dirigen desde los objetivos (las funciones) hacia los medios (el diseño). (Oviedo, 2015)

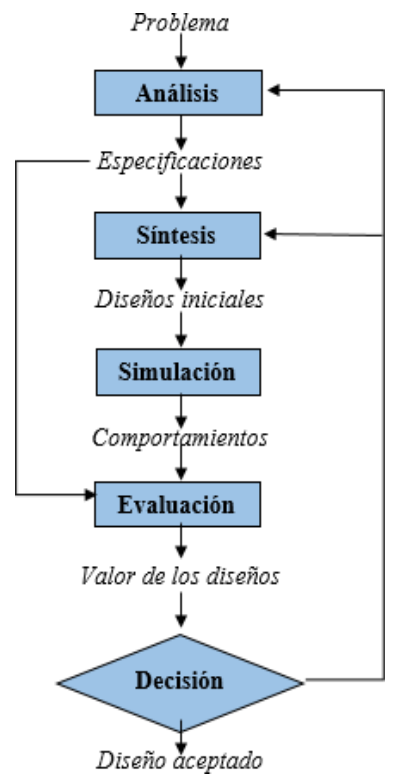

Figura 3. Ciclo básico del diseño mecánico 
- Metodología prescriptiva. Esta metodología realiza un enfoque que corresponde a contestar la pregunta ¿Cómo hacerlo? para esta metodología se recomienda seguir una secuencia o procedimientos para llegar a la posible solución, sin embargo, esta solución se establece dos tipos de modelos el modelo de fases y el modelo de artefacto. (Ribba, 2002)

- Modelo de fases. - Este modelo de fases permite estructurar un proceso de diseño o secuencias, para aplicar este modelo se hace referencia a la norma alemana VDI 2222 (1977). Esta norma hace énfasis al diseño modular, la cual establece que en cada módulo pueden existir 3 tipos de entradas y salidas como son las de control, material, energía y en el centro del recuadro la función principal que debe cumplir la máquina a diseñar. (Ribba, 2002)

- Modelo de artefacto. - Este modelo de artefacto se centra en la evolución de la información hasta obtener el diseño adecuado y/o final, en este modelo se encuentra el diseño concurrente que hace énfasis en la técnica QFD (DEPLOYMENT QUALITY FUCTION) / (DESPLIEGUE DE LA FUNCIÓN DE CALIDAD). (CROSS, Nigel, 1999)

Una vez evaluado todas las soluciones mediante los respectivos criterios de ponderación y haciendo uso de la matriz QFD se concluye que la mejor solución es un modelo de máquina briquetadora de residuos de café que está constituida con un sistema de compactación neumático semiautomático que comprende dos actuadores, además con sensores del tipo de final de carrera y temporizadores con el fin de obtener la briquetas de dimensiones indicadas, el sistema de expulsión de la briqueta se realiza mediante un actuador neumático, una vez salido del molde se extrae manualmente y se coloca en un sitio adecuado.

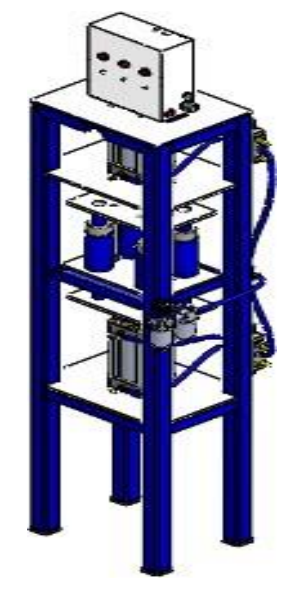

Figura 4. Prensa briquetadora modelado en SolidWorks 


\section{Análisis estático de resistencia mecánica.}

El análisis estático de resistencia mecánica realizado en el software ANSYS se basa en la utilización de método de elemento finito y la teoría de Von Mises.

- Método de elemento finito (MEF): es un método numérico para el acercamiento de soluciones de ecuaciones diferenciales parciales complicadas utilizado en diversos problemas de ingeniería, la simulación basa su cálculo mediante MEF.

- Teoría de Von Mises (teoría de energía de distorsión): Postula que la fluencia no es un fenómeno de tensión o compresión simples, sino que está relacionado con la energía proveniente de la distorsión del elemento de esfuerzo, para determinar la teoría de energía de distorsión se emplea la siguiente ecuación: (Vanegas, 2009).

$\sqrt{\sigma_{x}^{2}-\sigma_{x} \sigma_{y}+\sigma_{y}^{2}+3\left(\tau_{x y}\right)^{2}}=\frac{S_{y}}{n}$

Donde:

$\sigma_{x}$ es el esfuerzo normal en la dirección $x[\mathrm{MPa}]$

$\sigma_{y}$ es el esfuerzo normal en la dirección y [MPa]

$\tau_{x y}$ es el esfuerzo cortante en la dirección $x$ y [MPa]

$S_{y}$ es la resistencia a la fluencia. $[M P a]$

El análisis estático se realizó a la estructura la cual soportará los actuadores neumáticos, los pines de compactación y el molde con cargas distribuidas de $85 \mathrm{~N}$ y $25 \mathrm{~N}$ según donde se ubican estos elementos como indica la figura 4. La estructura se analiza con un material estructural ASTMA36. 


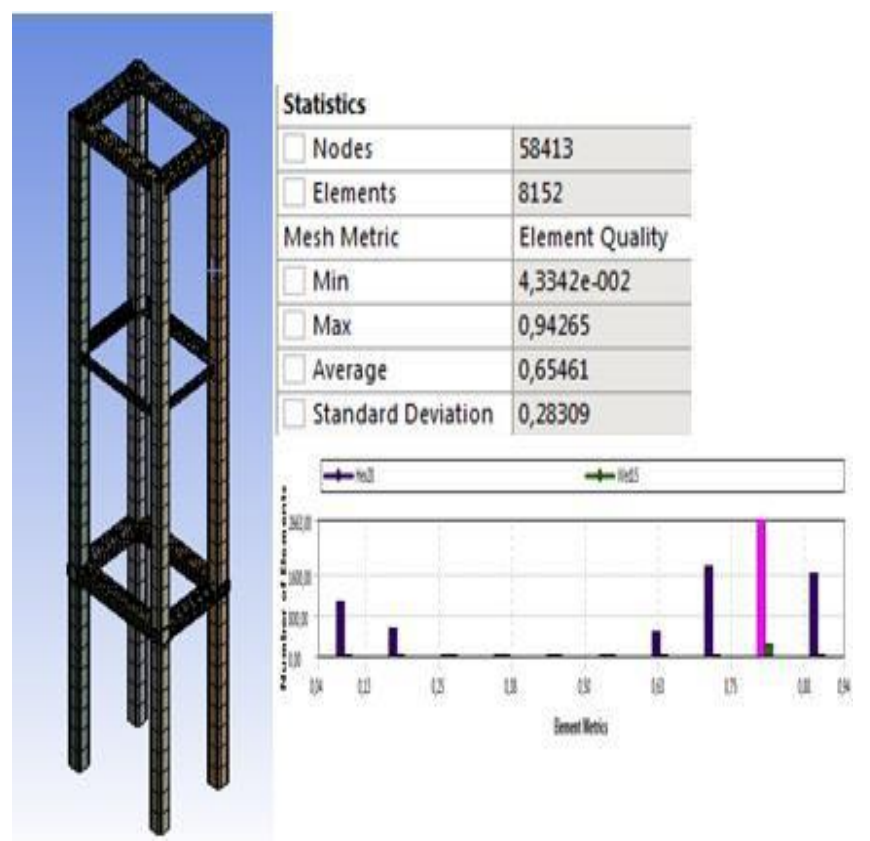

Figura 5. Mallado del soporte

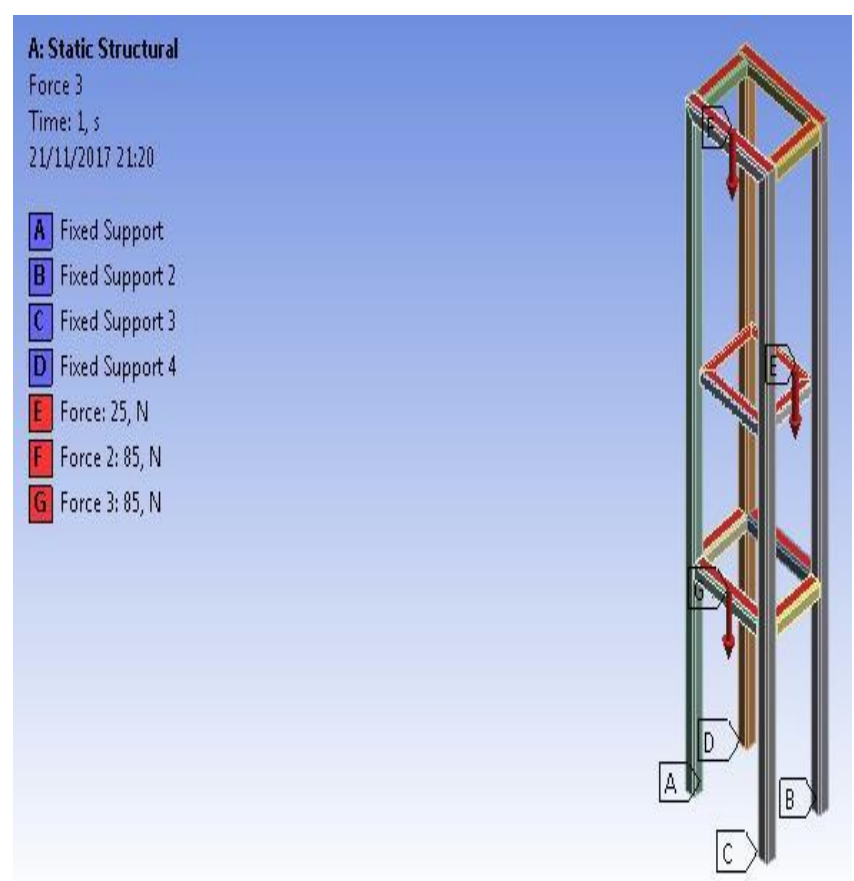

Figura 6. Cargas y apoyos 


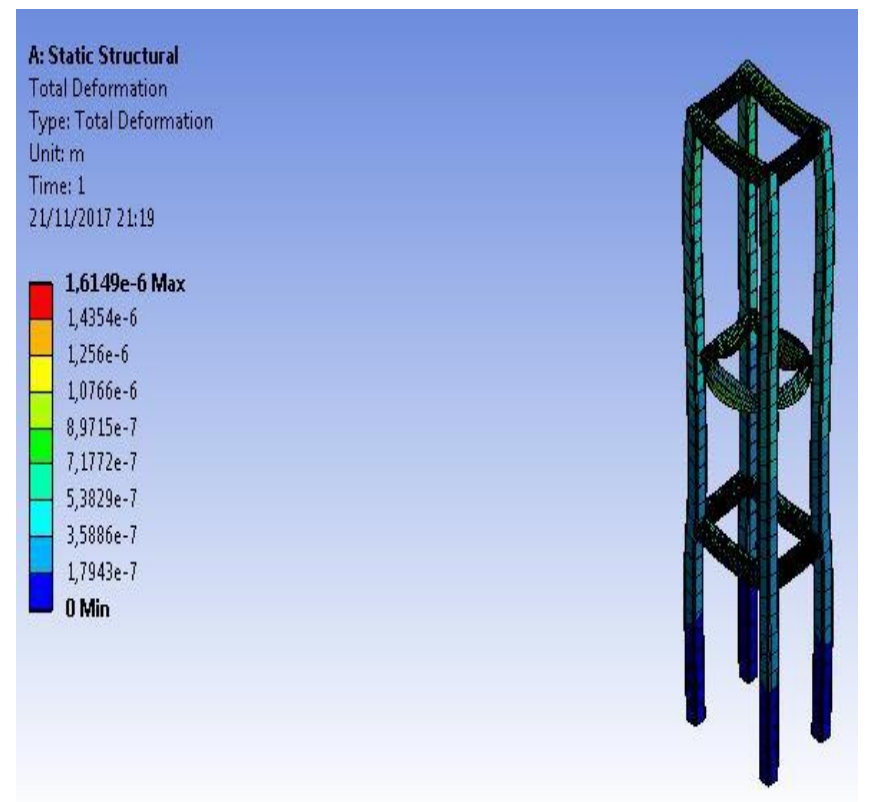

Figura 7. Deformación total del soporte

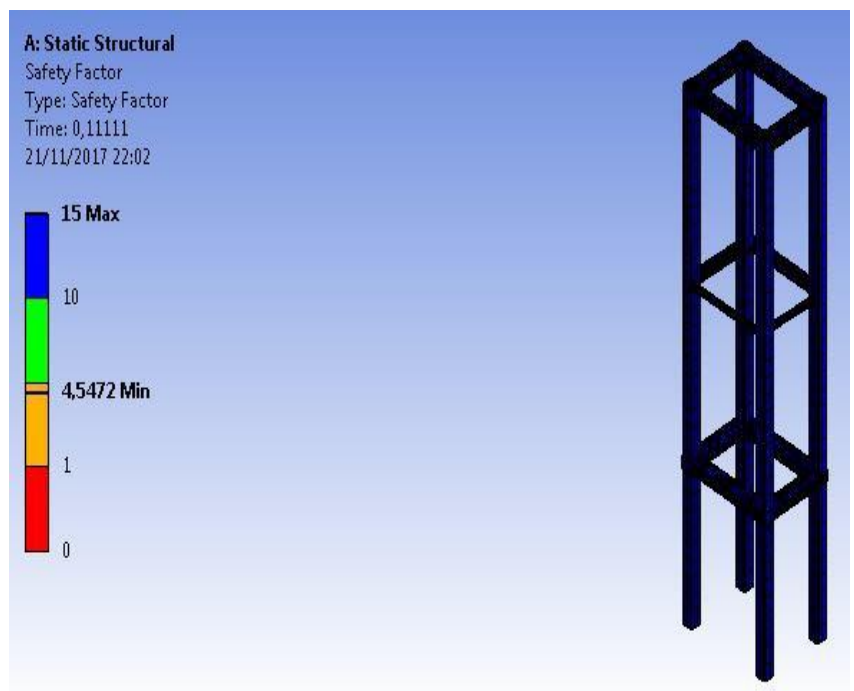

Figura 8. Factor de seguridad

La presión adecuada fue de 2,77 MPa para obtener una briqueta cilíndrica maciza de altura=50 $\mathrm{mm}$ y diámetro $=47 \mathrm{~mm}$, por lo tanto, la fuerza que debe tener el actuador neumático es 469,54 kgf (4606,1874 N), a este valor se debe sumar el peso de las placas, los pines de compactación y multiplicar por un factor de seguridad de 1,1 dando como resultado una fuerza de 50008,42 N.

Para seleccionar el actuador neumático según el monograma de la figura 9, se calcula la fuerza requerida y la presión de la línea de aire comprimido dando como resultado un actuador 
neumático de diámetro $100 \mathrm{~mm}$ y una fuerza de $549.5 \mathrm{kgf}$ en expulsión, sobrepasa la fuerza requerida para compactar a una presión de 2,77 MPa.

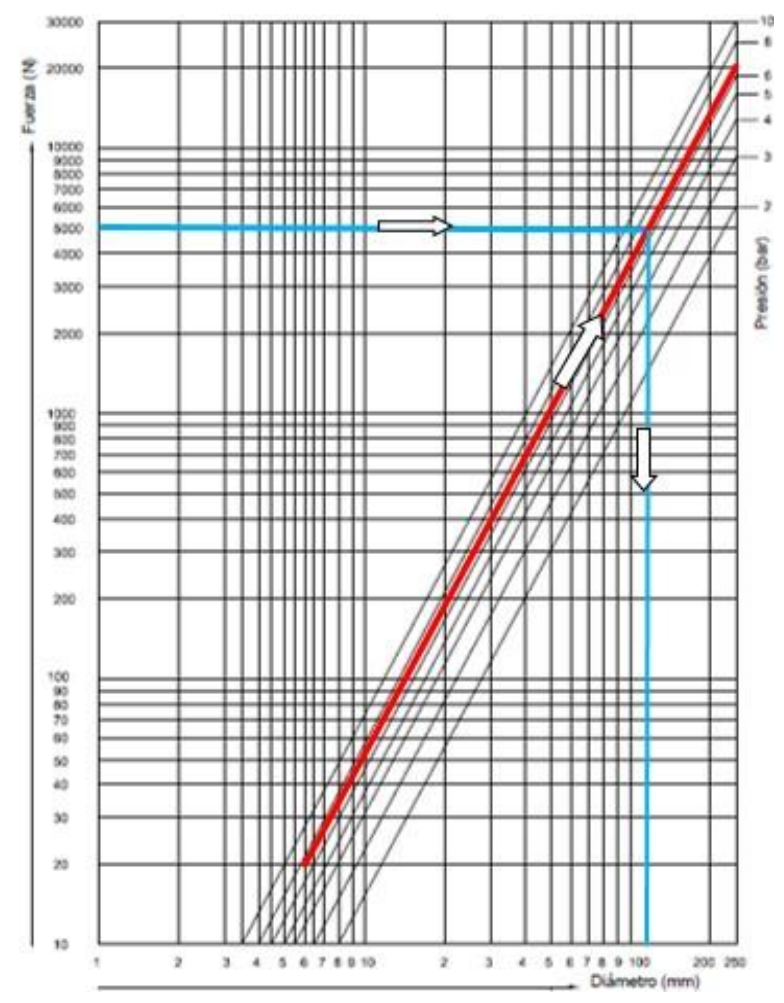

Figura 9. Monograma de selección de actuadores neumáticos

\section{Construcción de la máquina briquetadora.}

Realizado el análisis y selección de los componentes que contiene la máquina briquetadora se procede a la construcción, aplicando diversos procesos de manufactura como: corte, taladrado, rectificado, fresado, torneado y soldadura.

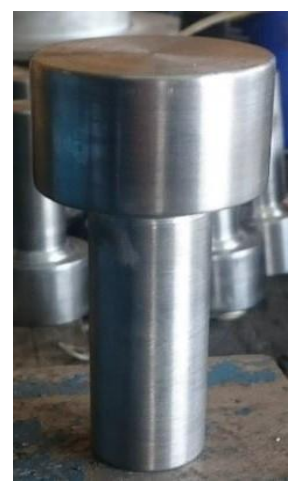

Figura 10. Cilindrado de los pines de compactación 


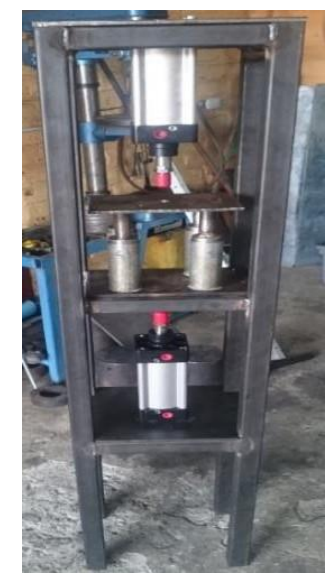

Figura 11. Aplicación de soldadura a la estructura

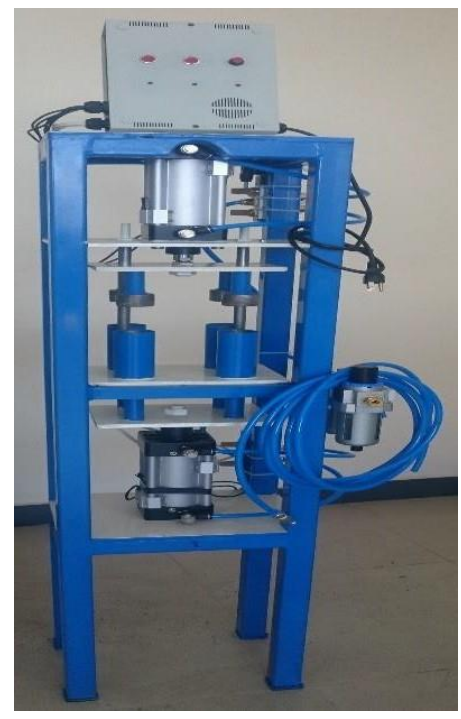

Figura 12. Máquina briquetadora neumática

\section{Obtención de briquetas y resultados de la caracterización física, energética y química.}

Logrando la mezcla deseada se procese a la elaboración de las briquetas estas son producidas mediante una máquina compactadora semi industrial, la misma que trabaja con una presión de compactación de 2,72 MPa, obteniendo así las briquetas de borra de café. 


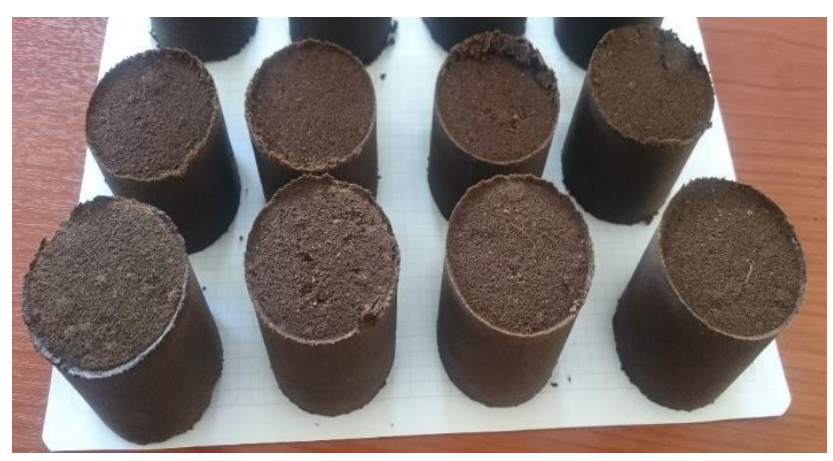

Figura 13. Briquetas obtenidas en la máquina briquetadora

Una vez obtenidas las briquetas de borra de café con almidón de yuca y dejar secar en un horno a $90{ }^{\circ} \mathrm{C}$ y durante 24 horas. También se puede secar al aire libre este secado se realiza por acción del viento se realiza en terrazas o en el campo su tiempo mínimo de duración es 8 días, este es un método ampliamente utilizado, en este tipo de secado las briquetas bajarán su humedad hasta establecer una relación de equilibrio entre su humedad interna y la del ambiente que les rodea. (FAO, 2014)

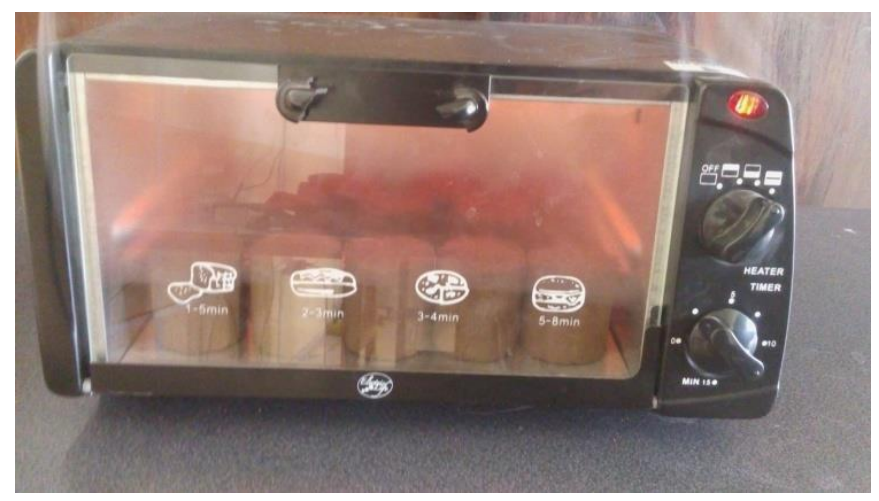

Figura 14. Proceso de secado al horno

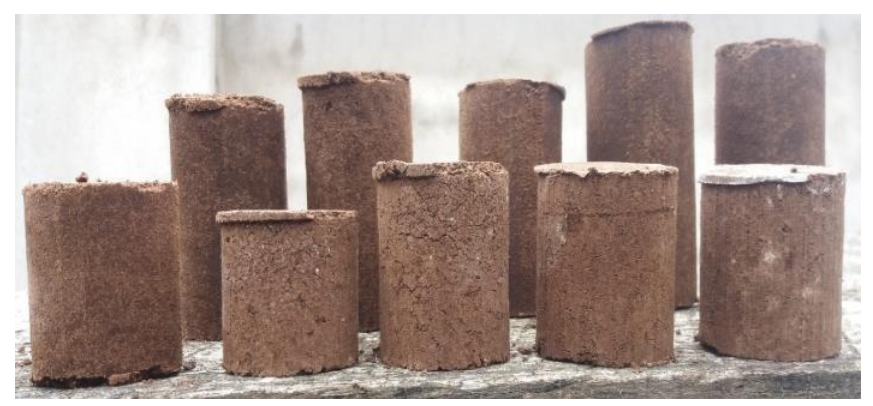

Figura 15. Proceso de secado al aire libre 
La caracterización de la biomasa, según Rincón (2014), perteneciente al Grupo de Investigación en Biomasa y Optimización Térmica de Procesos - BIOT, establece que para la caracterización de la biomasa se debe realizar la caracterización química, energética y física, y por ser la briqueta de borra de café procedente de biomasa se encuentra dentro de esta caracterización.

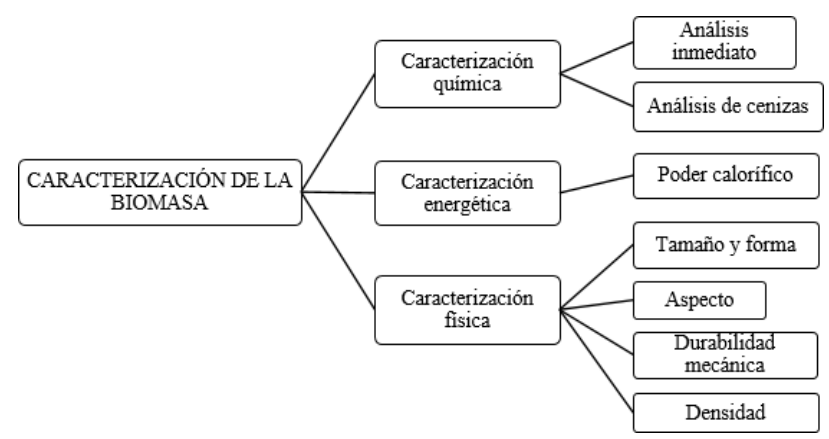

Figura 16. Caracterización de la biomasa

\section{A. Caracterización física}

Aspecto. - Se habla de la apariencia exterior e interior y de su color; la superficie exterior es rugosa, presenta pequeñas gritas y la superficie interior presenta pequeñas masas globulares por la adherencia del almidón de yuca al residuo de café marrón, su color es café.

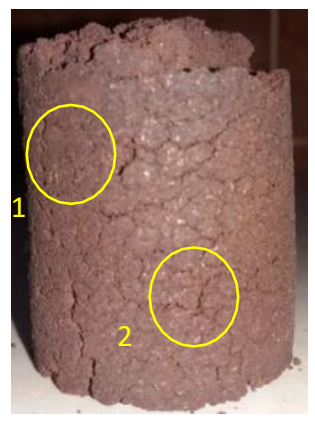

\section{1.- Agrietas}

2.- Superficie rugosa

Figura 17. Apariencia exterior de la briqueta de borra de café.

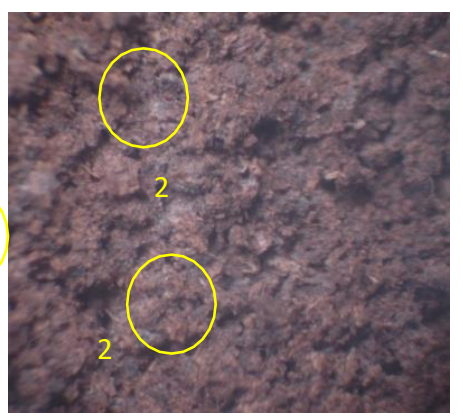

1.- Pequeñas cantidades de almidón de yuca

2.- Masas globulares

Figura 18. Apariencia interior de la briqueta de borra de café. 
Resistencia al aplastamiento. - Este ensayo fue realizado en el laboratorio de Resistencia de Materiales en la facultad de Mecánica de la ESPOCH en la cual se ensayaron 20 briquetas ya que es el número mínimo recomendado para un diseño experimental

Para este ensayo se emplea de 50 a 100 briquetas de la misma masa y se calcula el promedio ponderado de la carga de aplastamiento $(\mathrm{Rm})$, el valor obtenido debe corresponder con lo indicado en la Tabla 4. El $90 \%$ de las briquetas deben tener una resistencia individual mayor de $0,75 \mathrm{Rm}$.

Tabla 2. Requisitos de resistencia al aplastamiento

\begin{tabular}{|c|c|}
\hline $\begin{array}{c}\text { Masa de cada briqueta } \\
\text { en [g/briqueta] }\end{array}$ & $\begin{array}{c}\text { Rm, mínimo en } \\
\mathbf{N}(\mathbf{k g f})\end{array}$ \\
\hline 60 o más & $784,31(80)$ \\
\hline 40 & $588,23(60)$ \\
\hline 30 & $490,19(50)$ \\
\hline 20 & $392,15(40)$ \\
\hline
\end{tabular}

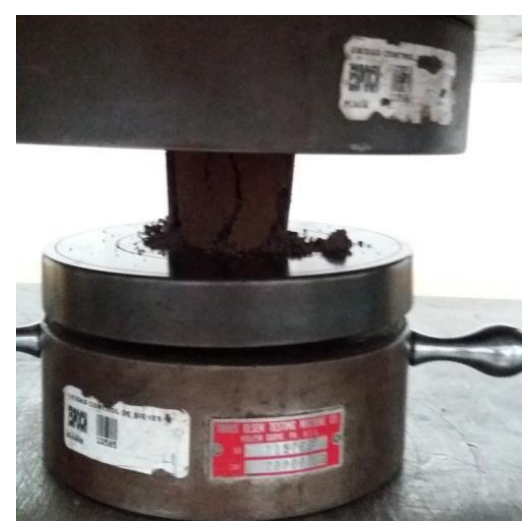

Figura 19. Aplicación de carga a la briqueta

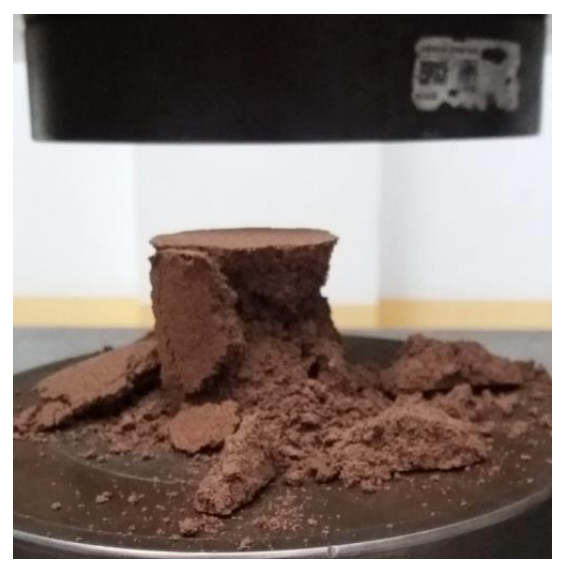

Figura 20. Briqueta de borra de café después del ensayo 
Tabla 3. Resistencia al aplastamiento de las briquetas de borra de café

\begin{tabular}{|c|c|c|c|}
\hline $\begin{array}{c}\text { Número de } \\
\text { briquetas }\end{array}$ & $\begin{array}{c}\text { Peso } \\
\text { (g/briqueta) }\end{array}$ & $\begin{array}{c}\text { Carga al } \\
\text { aplastamiento kgf (N) }\end{array}$ & $\begin{array}{c}\text { Altura de las } \\
\text { briquetas[mm] }\end{array}$ \\
\hline 20 & 40 & $24,24(237,74)$ & 50 \\
\hline
\end{tabular}

Verificando los valores de resistencia al aplastamiento de la Tabla 4 para $40 \mathrm{~g} / \mathrm{briqueta}$ se tiene $\mathrm{Rm}=60$ kgf, como el 90\% de las briquetas deben tener una resistencia individual mayor de 0,75 Rm, y al comparar con los valores obtenidos en la Tabla 1 se observa que las briquetas cumplen no cumplen con este requisito.

Densidad. - Para determinar la densidad se utilizó la siguiente fórmula:

$$
p=\frac{m}{V}
$$

Donde:

$\rho=$ Densidad $\left[\mathrm{kg} / \mathrm{m}^{3}\right]$

$m=$ Masa de la briqueta de borra de café $[\mathrm{kg}]$

$V=$ Volumen de la briqueta de borra de café $\left[\mathrm{m}^{3}\right]$

- Cálculo del volumen de la briqueta

$$
V=\frac{\pi D^{2} h}{4}=\frac{\pi(0,047 \mathrm{~m})^{2}(0,05 \mathrm{~m})}{4}=8,67 \times 10^{-5} \mathrm{~m}^{3}
$$

- Calculo de la densidad de la briqueta de borra de café

$$
\rho=\frac{m}{V}=\frac{0,04 \mathrm{~kg}}{8,67 \times 10^{-5} \mathrm{~m}^{3}}=461,36 \mathrm{~kg} / \mathrm{m}^{3}
$$

Forma y tamaño. - Su forma es cilíndrica y las dimensiones geométricas son h: 50 [mm]; d: $47[\mathrm{~mm}]$. (Ver fig. 7)

A continuación, se presenta las características geométricas de las briquetas de borra de café con almidón de yuca. 


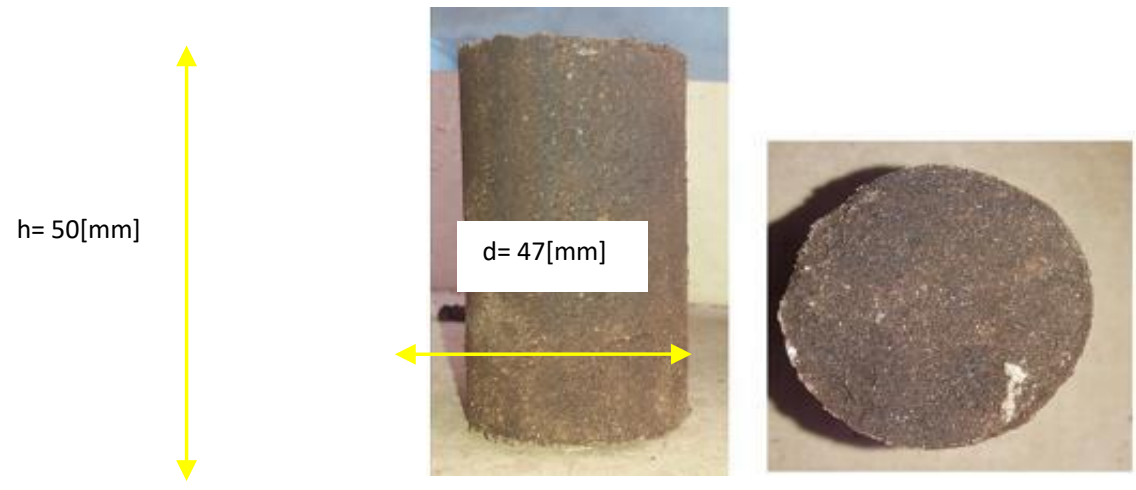

Figura 21. Características geométricas de las briquetas de borra de café

\section{B. Caracterización energética.}

Para la caracterización energética se debe analizar el poder calorífico superior experimental utilizando la bomba calorimétrica, el resultado obtenido se muestra en la Tabla 4, el mismo que fue realizado en el laboratorio del DPEC de la facultada de Ingeniería Química de la Universidad Central del Ecuador.

Tabla 4. Resultado del poder calorífico de la briqueta de borra de café

\begin{tabular}{|c|c|}
\hline Determinación & Resultado \\
\hline $\begin{array}{c}\text { Poder calorífico } \\
\text { superior }[\mathbf{M J} / \mathbf{k g}]\end{array}$ & 17,2118 \\
\hline
\end{tabular}

También el cálculo del poder calorífico teórico se realiza mediante la ecuación de la energía de alimentos utilizando los factores de Atwater, establecidos en la ecuación (1) y con este resultado se procede a calcular el error porcentual existente.

$$
\text { Poder calorifico }(\text { Kcal/ } 100 g)=A+B+C \quad \text { Ec. }(2)
$$

Donde:

$\mathrm{A}=(4 \mathrm{Kcal}) *(\%$ Carbohidratos totales $)$

$\mathrm{B}=(9 \mathrm{Kcal}) *(\%$ Grasas $)$

$\mathrm{C}=(4 \mathrm{Kcal}) *(\%$ Proteína $)$ 
Ecuación de carbohidratos totales: (Pastor, 2016)

$$
\begin{gathered}
\text { Carbohidratos totales }=100- \\
\text { (\%Humedad }+\% \text { Proteínas } \\
+\% \text { Grasas }+\% \text { Cenizas })
\end{gathered}
$$

Ec.

Resultados del PCS mediante la ecuación de la energía de alimentos (análisis teórico)

\section{Cálculo de los carbohidratos totales:}

Carbohidratos totales $=100-(9,12+12,56+12,89+1,76)$

Carbohidratos totales $=63,67 \%$

\section{Cálculo de poder calorífico teórico:}

PCS $($ Kcal $/ 100 g)=4 *(63,67)+9 *(12,89)+4 *(12,56)$

$\mathrm{PCS}=(420,93 \mathrm{Kcal} * 1000 \mathrm{~g}) /(100 \mathrm{~g} * 1 \mathrm{KG})=4209,3 \mathrm{Kcal} / \mathrm{Kg}$

$\mathrm{PCS}=17,622 \mathrm{MJKg}$

Error porcentual entre el valor del poder calorífico obtenido experimentalmente y el valor del poder calorífico teórico es:

$\%$ error $=\frac{\| \text { teórico }- \text { experimental } \|}{\text { teórico }} * 100$

$\%$ error $=\frac{|17,62-17,21|}{17,62} * 100$

$\%$ error $=2,33$

El error que presenta los cálculos obtenidos experimentalmente y teóricamente es de 2,33\%, error que se obtiene porque son dos procedimientos distintos

\section{Caracterización Química}

Análisis inmediato y análisis de cenizas. - En el desarrollo del análisis inmediato se debe determinar los porcentajes de proteína, humedad, fibra y grasas, y para el análisis de cenizas se debe especificar el porcentaje de cenizas; todos estos resultados se pueden observar en la Tabla 5, 
los mismos que fueron obtenidos en el laboratorio del CESTTA de la facultada de Ciencias de la ESPOCH.

Tabla 5. Resultado del análisis bromatológico de una briqueta de borra de café con almidon de уиса

\begin{tabular}{|c|c|}
\hline PARÁMETRO & RESULTADO \\
\hline Proteína [\%] & 12,56 \\
\hline Humedad [\%] & 9,12 \\
\hline Cenizas [\%] & 1,76 \\
\hline Fibra [\%] & 17,37 \\
\hline Grasas [\%] & 12,89 \\
\hline
\end{tabular}

Contenido de humedad. - Conociendo los rangos de humedad y mediante el análisis bromatológico se obtienen el resultado de humedad del 9.12\% el mismo que está dentro del rango según (Camps, et al., 2008) y (Rodriguez, et al., 2010)

Contenido de cenizas. - El resultado del contenido cenizas es 1,76\% de acuerdo al análisis bromatológico este resultado es beneficioso debido a que el contenido de cenizas debe ser inferior al 4\%, ya que si sobre pasa puede causar corrosión.

\section{Ensayo de incineración de las briquetas y el carbón vegetal.}

Para la prueba de incineración se ensaya varias muestras de briquetas de borra de café y de carbón vegetal tomando en cuenta que cada muestra debe tener peso de 0,5; 1 y 1,5 lb, las mismas que son colocadas en un asadero y posteriormente se procede a su encendido y toma de temperaturas cada 5 minutos, esto se realiza mediante la utilización de un pirómetro, después se realiza el mismo procedimiento con el carbón vegetal, para luego realizar la comparación respectiva.
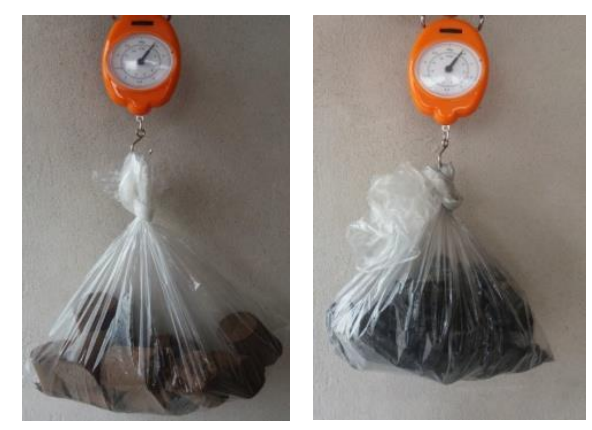

Figura 22. Muestras de briquetas de borra de café y carbón vegetal 


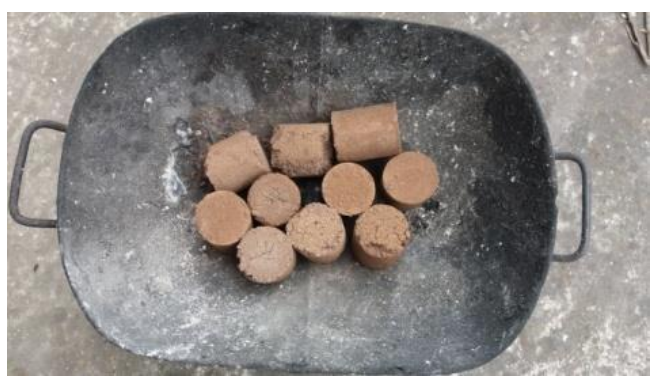

Figura 23. Colocación de las briquetas de borra de café en el asadero
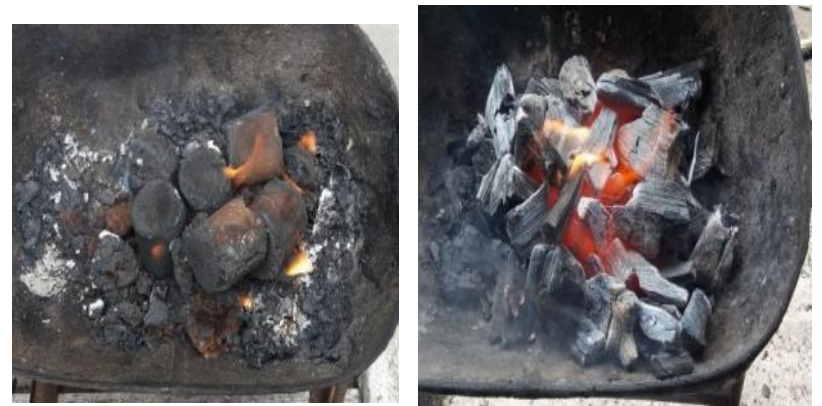

Figura 24. Encendido de briquetas de borra de café y carbón vegetal
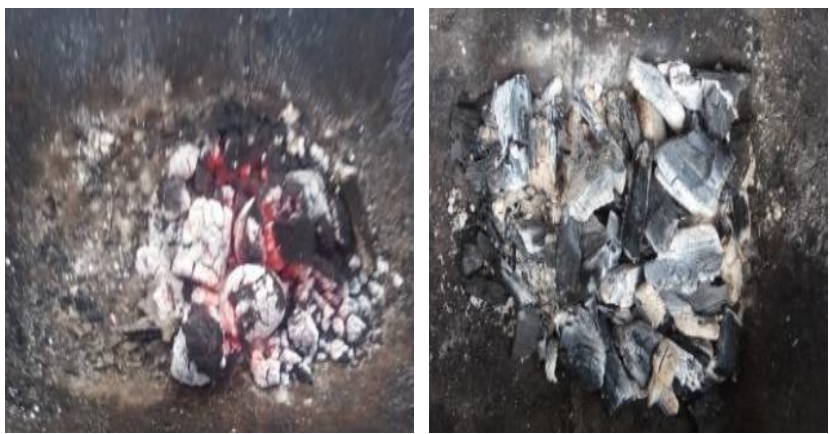

Figura 25. Brasa de las briquetas de borra de café y el carbón vegetal

A continuación, se muestra curvas de tiempo y de temperatura de las briquetas de residuos de café y del carbón vegetal encendidas y en brasa respectivamente para posteriormente realizar una comparación de temperaturas.

Curvas de Tiempo vs Temperatura de las briquetas de residuos de café de 0,5; 1 y 1,5 lb. 
Tiempo vs Temperatura (Tipo llama)

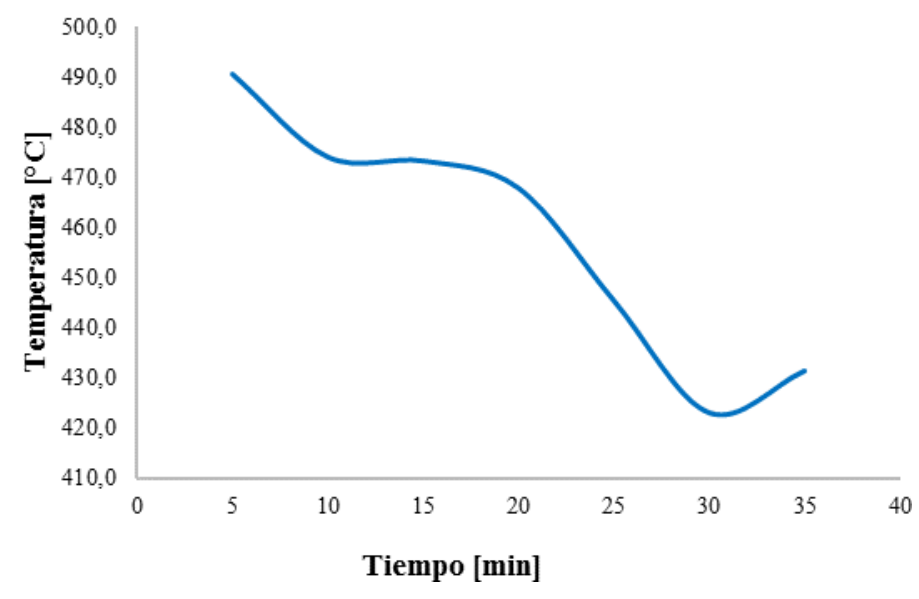

Figura 26. Curva de Tiempo vs Temperatura encendido tipo llama (0,5 lb)

Tiempo vs Temperatura (Tipo brasa)

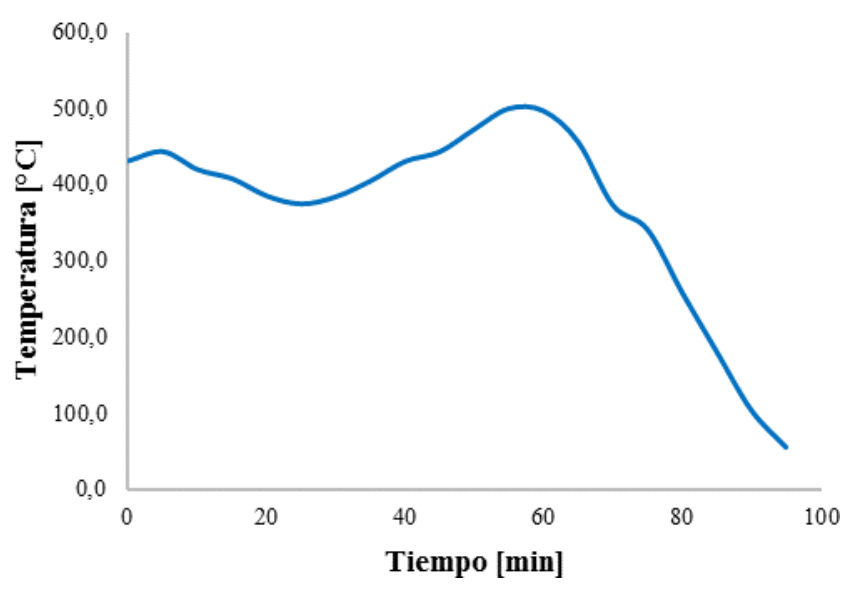

Figura 27. Curva Tiempo vs Temperatura encendido tipo brasa $(0,5 \mathrm{lb})$ 
Tiempo vs Temperatura (Tipo llama)

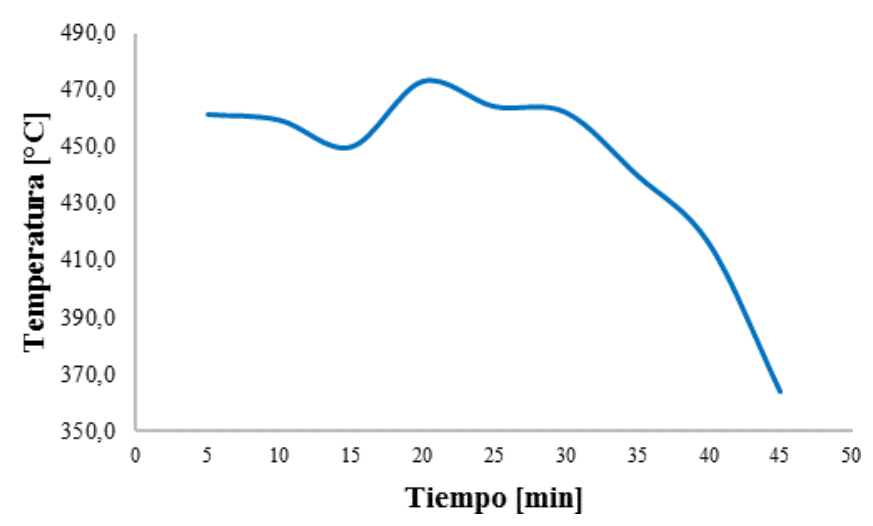

Figura 28. Curva de Tiempo vs Temperatura encendido tipo llama $(1 \mathrm{lb})$

Tiempo vs Temperatura (Tipo brasa)

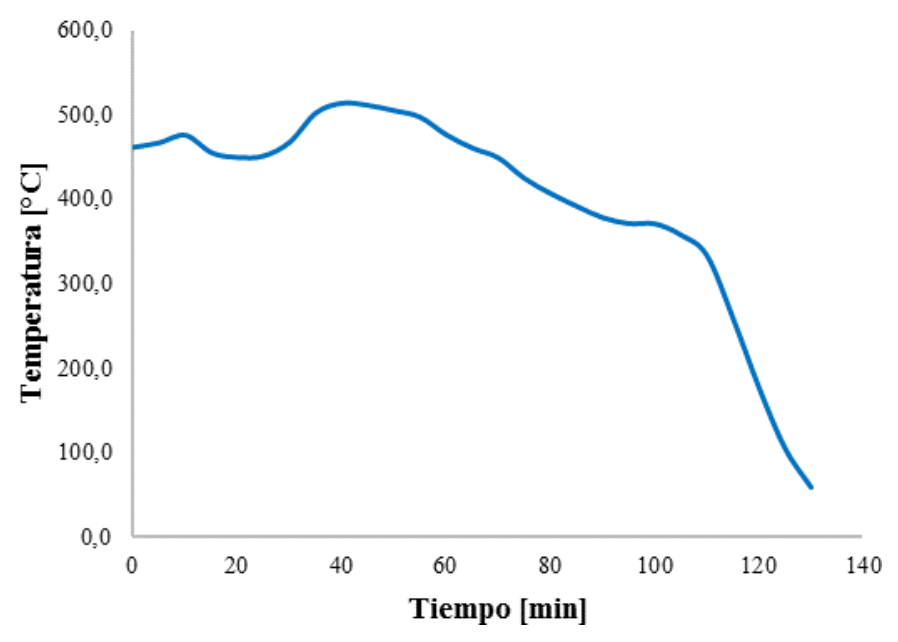

Figura 29. Curva Tiempo vs Temperatura encendido tipo brasa $(1 \mathrm{lb})$ 
Tiempo vs Temperatura (Tipo llama)

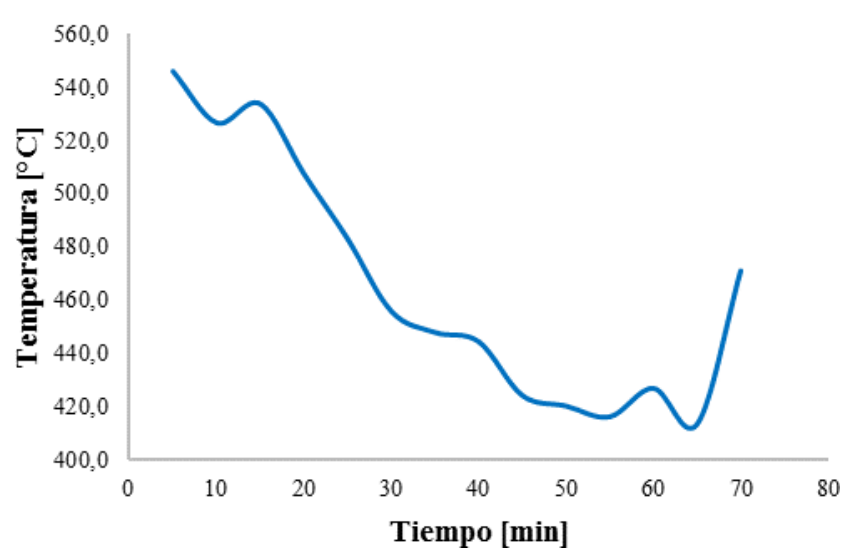

Figura 30. Curva de Tiempo vs Temperatura encendido tipo llama $(1,5 \mathrm{lb})$

Tiempo vs Temperatura (Tipo brasa)

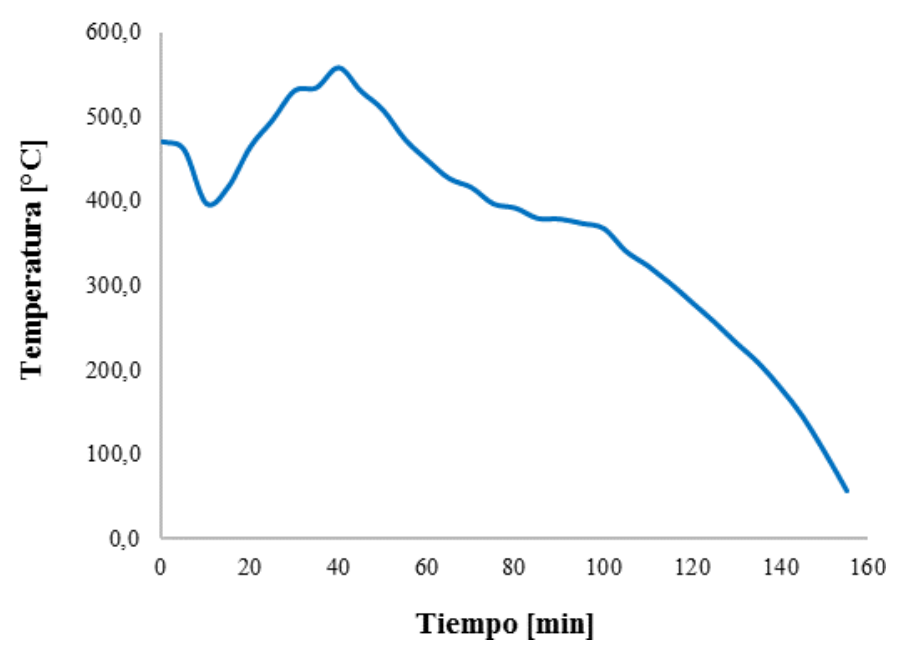

Figura 31. Curva Tiempo vs Temperatura encendido tipo brasa

$(1,5 \mathrm{lb})$ 
Curvas de Tiempo vs Temperatura de carbón vegetal de 0,$5 ; 1$ y 1,5lb.

Tiempo vs Temperatura (Tipo llama)

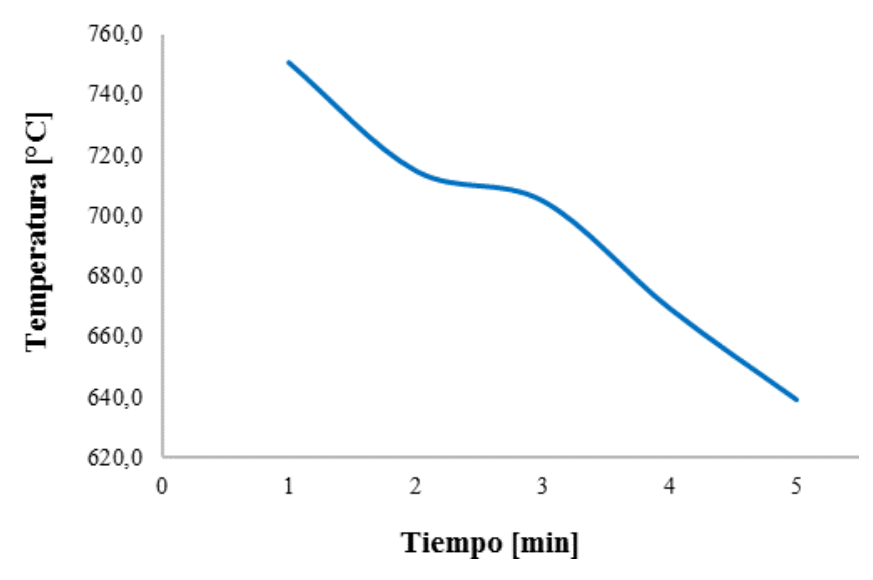

Figura 32. Curva vs Temperatura del carbón encendido tipo llama (0,5lb)

Tiempo vs Temperatura (Tipo brasa)

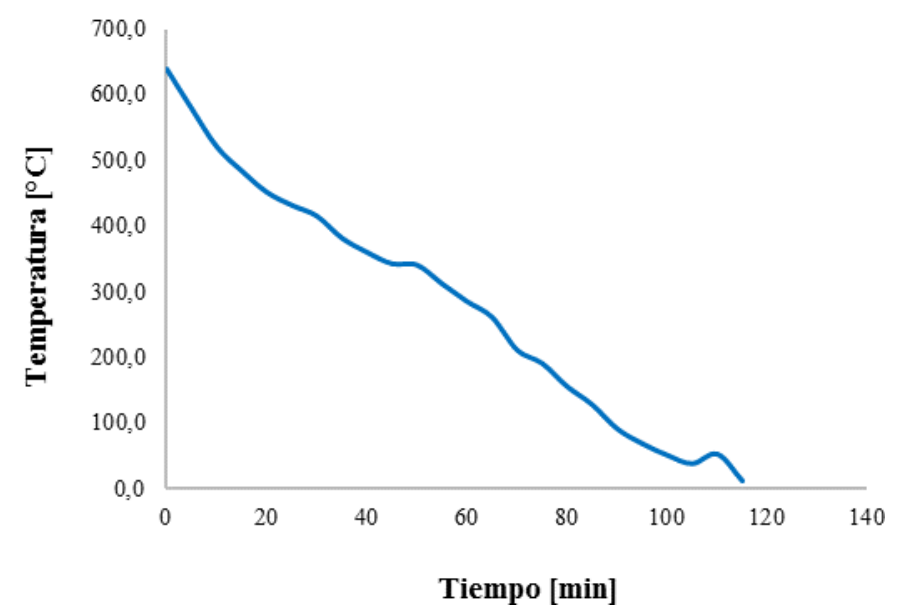

Figura 33. Curva Tiempo vs Temperatura del carbón vegetal encendido tipo brasa $(0,5 \mathrm{lb})$ 


\section{Tiempo vs Temperatura ( Tipo llama)}

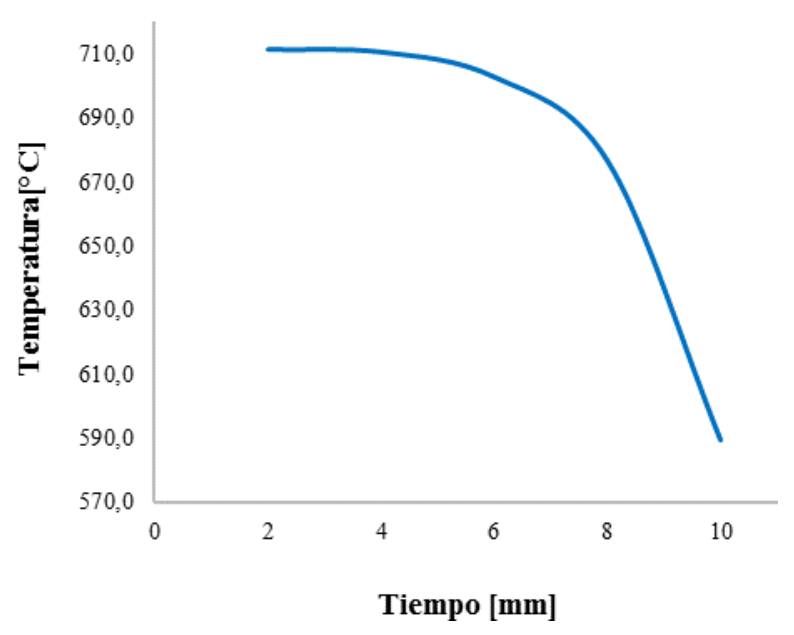

Figura 34. Curva Tiempo vs Temperatura del carbón encendido tipo llama (1 lb)

\section{Tiempo vs Temperatura (Tipo brasa)}

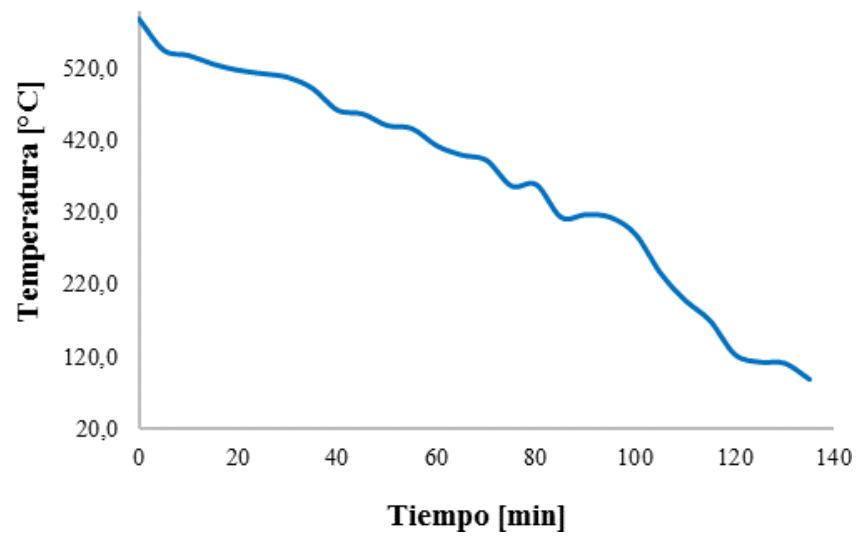

Fig. 29: Curva Tiempo vs Temperatura del carbón vegetal encendido tipo brasa (1 lb) 


\section{Tiempo vs Temperatura (Tipo llama)}

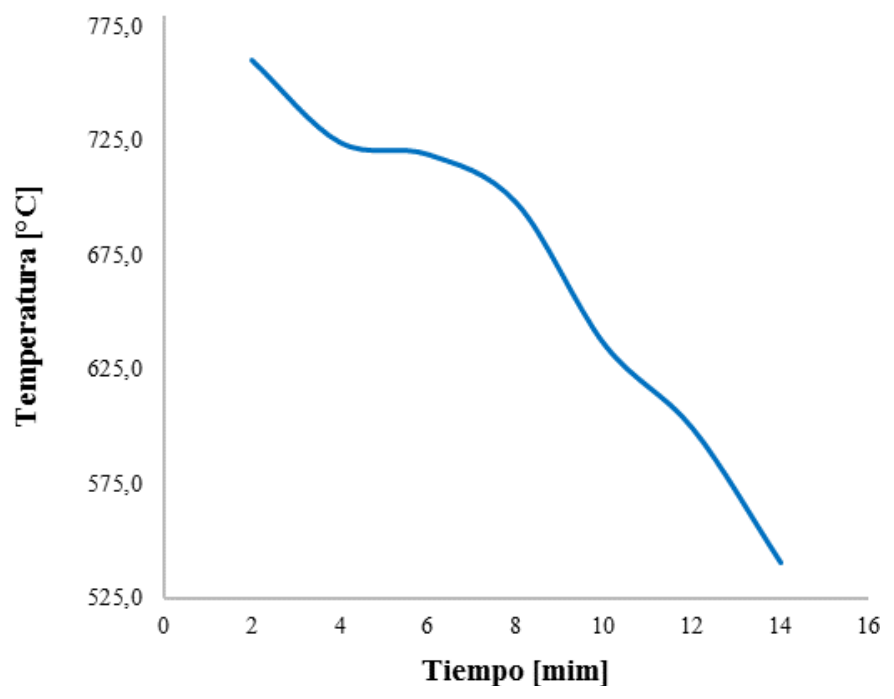

Figura 35. Curva Tiempo vs Temperatura del carbón vegetal encendido tipo llama $(1,5 \mathrm{lb})$

Tiempo vs Temperatura (Tipo brasa)

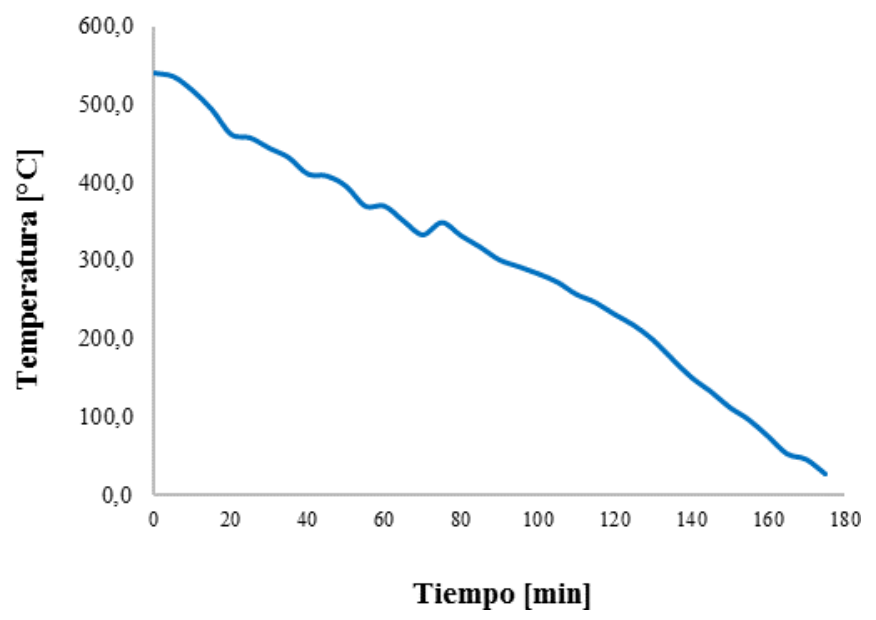

Figura 36. Curva Tiempo vs Temperatura del carbón vegetal encendido tipo brasa (1,5lb)

\section{Discusión}

A continuación, se muestran gráficos de Peso vs Temperatura y Peso vs Tiempo de las briquetas de residuos de café y del carbón vegetal de las muestras a 0,5 lb, $1 \mathrm{lb}, 1,5 \mathrm{lb}$ los cuales nos ayudará a identificar sus posibles aplicaciones. 
Peso vs Temperatura (Tipo Ilama)

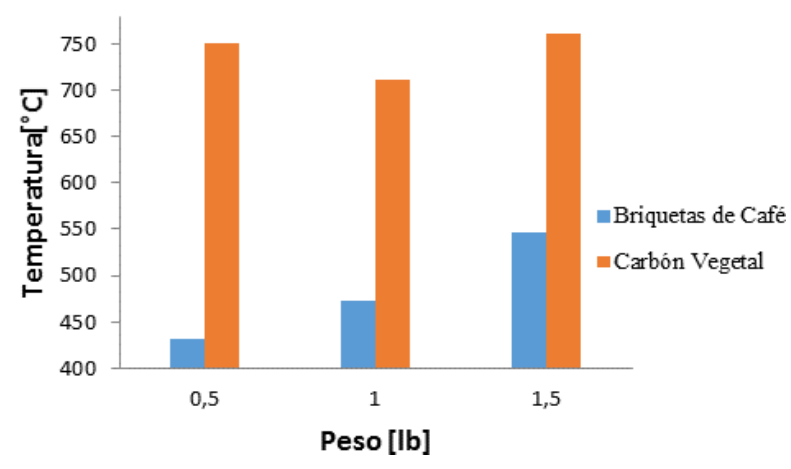

Figura 37. Peso y temperaturas de las briquetas de borra de café y carbón vegetal encendido tipo llama

\section{Peso vs Temperatura(tipo brasa)}

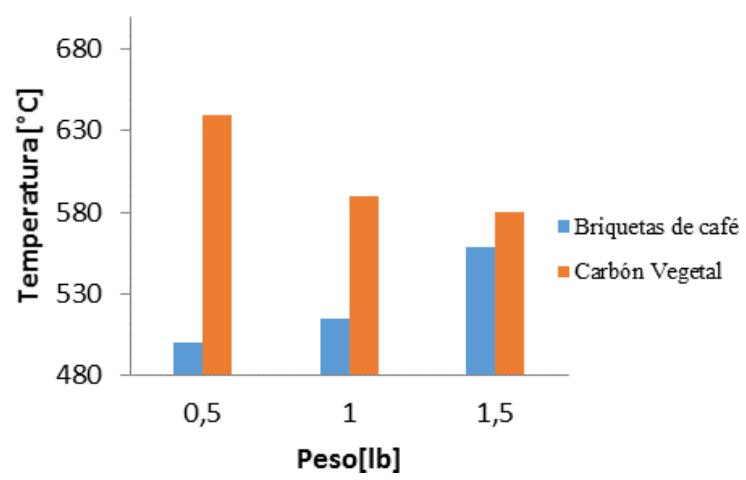

Figura 38. Peso y temperaturas de las briquetas de borra de café y carbón vegetal encendido tipo brasa

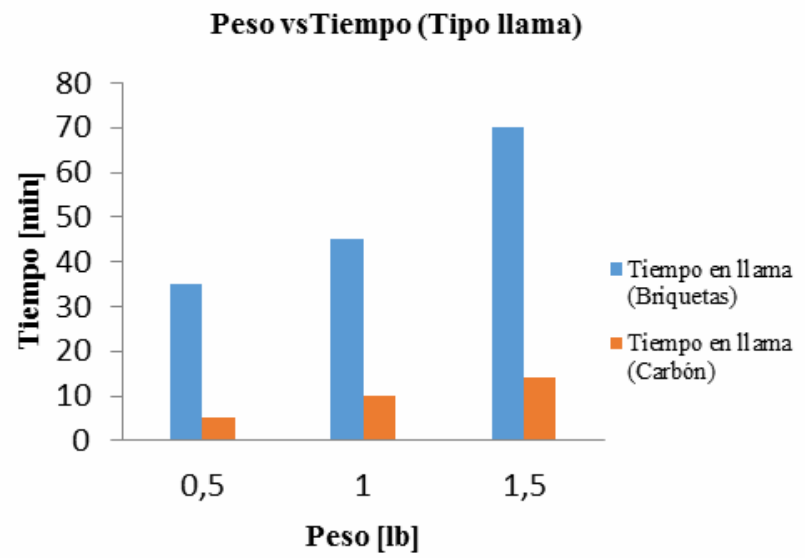

Figura 39. Peso y tiempo de las briquetas de borra de café y carbón vegetal encendido tipo llama 
Peso vs Tiempo (tipo brasa)

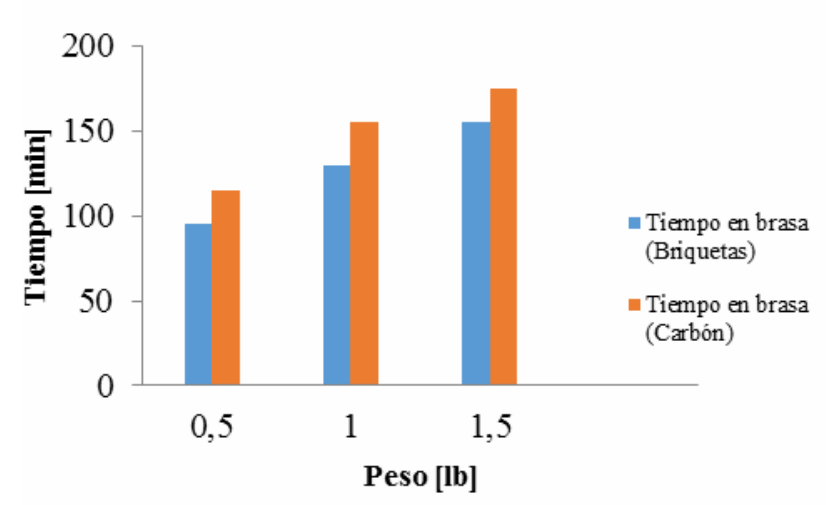

Figura 40. Peso y tiempo de las briquetas de borra de café y carbón vegetal encendido tipo brasa.

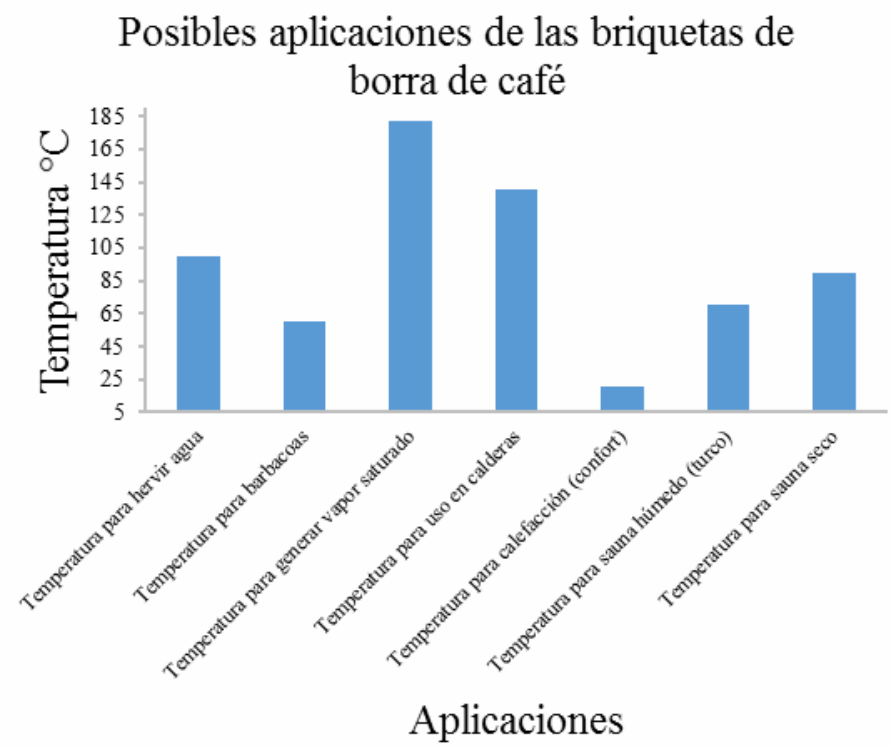

Figura 41. Posibles aplicaciones de las briquetas de borra de café según su temperatura de funcionamiento.

\section{A. Comparación de poderes calóricos con otros combustibles.}

En la tabla 5 se observa el valor del poder calorífico de los biocombustibles más utilizados en la industria los mismos que se encuentran ordenados de mayor a menor, el mismo que fueron obtenidos por diferentes autores. (Blanco, 2015) (Cross, 1999) (Vanegas, 2009) 
Conociendo el resultado del PCS de nuestras briquetas y mediante una comparación de poderes caloríficos con los demás combustibles se puede mencionar sus posibles aplicaciones de esta briqueta de borra de café:

La utilización más común de estas briquetas puede aplicarse para la generación de energía calorífica por lo tanto puede ser utilizado para calefacción, estufas de leña, para la generación de agua caliente, para utilización en barbacoas, etc.

Tabla 5. Resultado del poder calorífico de combustibles

\begin{tabular}{|l|c|}
\hline Combustible & PCS MJ/kg \\
\hline Carbón vegetal & 32,8 \\
\hline Corteza de pino & 20,4 \\
\hline Tallos de café & 19,75 \\
\hline Bagazo seco & 19,2 \\
\hline Residuo de maíz & 18,4 \\
\hline $\begin{array}{l}\text { Briquetas de residuos de } \\
\text { café }\end{array}$ & 17,62 \\
\hline Briquetas de aserrín & 17,52 \\
\hline Papel & 17,5 \\
\hline Cascarilla de arroz & 17 \\
\hline Celulosa & 16,5 \\
\hline Cáscara de trigo & 15,8 \\
\hline Pulpa de café & 15,8 \\
\hline $\begin{array}{l}\text { Briquetas de cascarilla de } \\
\text { arroz }\end{array}$ & 15,3 \\
\hline Cascarilla de arroz & 13,8 \\
\hline Paja seca de cebada & 13,4 \\
\hline Viruta seca & 13,4 \\
\hline Paja seca de trigo & 12,5 \\
\hline Bagazo húmedo & 10,5 \\
\hline Serrín húmedo & 8,4 \\
\hline Residuos de coco verde & 4,3 \\
\hline Cortezas de caña & 4 \\
\hline
\end{tabular}

\section{Conclusiones}

- $\quad$ Teniendo en cuenta el diseño de la máquina se procedió a modelar la estructura y luego se sometido a un análisis estático estructural en el programa ANSYS en base al criterio de Von 
Mises, el mismo que nos permitió determinar su deformación máxima y su factor de seguridad, obteniendo así unos resultados de 1,61e-6 [mm] en deformación máxima en la base de los moldes de la briqueta y un valor de 4,54 como factor de seguridad mínimo en la estructura.

- $\quad$ En cuanto a la forma de las briquetas se adoptó una configuración cilíndrica maciza ya que es una de las formas más óptimas, estas briquetas tienen las siguientes dimensiones geométricas; diámetro de la briqueta de $47 \mathrm{~mm}$, longitud de la briqueta $50 \mathrm{~mm}$.

- Las briquetas secadas al aire libre contienen una humedad de 9,12\% ya que este parámetro es uno de los importantes para fabricar briquetas cabe recalcar que establece un rango de humedad entre el $8-15 \%$, por lo tanto, las briquetas obtenidas se encuentran dentro del rango permisible.

- $\quad$ El poder calorífico bruto obtenido de las briquetas de borra de café se calculó de 17,21 $\mathrm{MJ} / \mathrm{kg}$ mediante la bomba calorimétrica (resultado experimental) mientras que aplicando la ecuación de energía de alimentos se obtiene 17,62 MJ/kg (resultado teórico), por lo tanto, son consideradas como briquetas ya que cumplen con el poder calorífico mínimo necesario de acuerdo a la norma NTC-2060.

- Debido que las briquetas pueden ser transportadas en diferentes formas se procede a determinar su resistencia al aplastamiento el mismo que está en función del peso de las briquetas, estas presentan un valor promedio de 24,24 $\mathrm{Kgf}(237,74 \mathrm{~N})$, este valor no cumple el rango minino establecido por la norma NTC-2060, debido a que las briquetas ensayadas tiene un peso aproximado de $40 \mathrm{~g} / \mathrm{briqueta}$ y el valor requerido para este peso es de $60 \mathrm{kgf}(588,23 \mathrm{~N})$, por lo tanto las briquetas obtenidas no cumplen con este requisito.

Las briquetas obtenidas presentan un poder calorífico de $17,21 \mathrm{MJ} / \mathrm{kg}$ por lo tanto se puede concluir que estas briquetas son un sustituto del carbón vegetal, aunque presente un poder calorífico inferior al carbón vegetal debido que las briquetas presentan más duración en tipo llama y es suficiente para la cocción de alimentos.

- $\quad$ Identificando el comportamiento de las briquetas de borra de café y del carbón vegetal (Peso vs Temperatura) y (Peso vs Tiempo) se concluye que las briquetas de borra de café pueden ser utilizadas en diferentes aplicaciones como: calefacción, cocción, asaderos, generación de 
vapor, sauna húmedo y sauna seco, etc. debido a que las briquetas, por ser un biocombustible densificado, aumenta la eficiencia de combustión y la densidad energética.

\section{Referencias Bibliográficas}

HU, J., Ley, T. et al, Económico, la evaluación social y ambiental de briqueta combustible a partir de residuos agrícolas - un estudio sobre la fabricación de briquetas matriz plana usando tallo de maíz energía, v. 64, p.557-566, 2014.

SILVA, CA Técnica-Económica Estudio de compresión de residuos de la madera con fines energéticos, Tesis de maestría de la Facultad de Ingeniería Mecánica, UNICAMP, Campinas, SP, Brasil, 2007.

FAO, DEPARTAMENTO FORESTAL de la. 2012. Datos y cifras globales de productos forestales. Roma: División de Economía, Políticas y Productos Forestales FAO, 2012.

PELÁEZ, Manuel \& ESPINOZA, Juan. 2015. Energías renovables en el ecuador situación actual, tendencias y perspectivas. Cuenca: Universidad de Cuenca, 2015. ISBN 978-9978-14-317-9.

Instituto Nacional de Eficiencia Energética y Energías Renovables, (INER). 2016. Análisis de las oportunidades de I+ D+ ien eficiencia energética y energías renovables en el Ecuador. Quito: s.n., 2016. ISBN 978-9942-8620-1-3.

FILIPPETO, D., Residuos de plantas de fabricación de briquetas: la viabilidad técnicoeconômica y potencial de mercado. MSc. Facultad Tesis de Ingeniería Mecánica, Campinas, Campinas, Brasil, 2008. Estudio

JANCZAK, J. Técnicas simples para la obtención de combustibles básicos [en línea].Nairobi: FAO, 1981[Consulta: 10 mayo 2017]. Disponible en: http://www.fao.org/docrep/p2070s/p2070s06.htm

MADRUGA, E. Combustibles sólidos de baja densidad. (Primera parte). [en línea]. Cuba: 1981[Consulta: 17 mayo 2017]. Disponible en: http://www.cubasolar.cu/biblioteca/energia/Energia13/HTML/articulo03.htm

ORGANIZACIÓN DE LAS NACIONES UNIDAD PARA LA ALIMENTACIÓN Y LA AGRICULTURA. FAO. El mercado de almidón añade valor a la yuca [en línea].Brasili: 
Departamento de agricultura y proiteccion del consumidor FAO, 2006 [Consulta: 28 de junio 2017]. Disponible en: http://www.fao.org/ag/esp/revista/0610sp1.htm

OVIEDO, N. Aglutinante usar para briquetas [en línea], 2015, [Consulta: 25 junio 2017]. Disponible en: http://www.todoexpertos.com/preguntas/68coo3i6x8xh7rgs/que-aglutinante-usarpara-briquetas -ii

RIBBA, C., Diseño Concurrente. Barcelona-España: Edicions UPC, 2002, pp.45-67

BLANCO E., Metodología para el diseño de máquinas. Barcelona-España: Edicions UPC, 2015, pp. 25-26.

CROSS, N. Métodos de Diseño: Estrategias para el diseño de máquinas. Mexico-Mexico D.F: Limusa Wiley, 1999. pp 34-38.

Vanegas L. Useche, (2009). “Conceptos básicos sobre el diseño de máquinas” Primera edición. ORGANIZACIÓN DE LAS NACIONES UNODAD PARA LA ALIMENTACIÓN Y LA AGRICULTURA, FAO. 2014. Bioenergía y seguridad alimentaria evaluación (BEFS RA) BRIQUETAS. s.1.: FAO, 2014, p. 20.

RINCÓN, S. Sistemas Energéticos con biomasa. Bogotá- Colombia, 2014 pp.15-24

PASTOR, Mario. Apuntes de fundición. ESPOCH. Riobamba.

GLADSTONEA.S, et al. Targeting briquetting as an alternative fuel source in Tanzania. Tanzania: Elsevier Ltd., 2014, Vol. 1, pp. 3-5.

Departamento de Ciencia de los Alimentos y Biotecnología (DECAP), Cálculo los carbohidratos totales, Ecuador-Quito, 2012.

NORMA TECNICA COLOMBIANA, NTC-2060. 1987. Briquetas combustibles oara uso doméstico. Bogotá: Editada por el Instituto Colombiano de Normas Técnicas y Certificación (ICONTEC), 1987. pp. 4-6. Vol. 1

CAMPS, Manuel y MARCOS, Francisco. 2008. Los biocombustibles. 2da. Madrid-España: Ediciones Mundi-Prensa, 2008. pp. 137-168. 978-84-8476-360-4. 
RODRIGUEZ, Nelson \& ZAMBANO, Diego. 2010. Los subproductos del café:fuente de energía renovable. Chinchiná,Caldas : CENICAFÉ, 2010. pp. 4. 0120-0178.

LEE LELAND HITE. Briquetas de biomasa caseras II. La prensa [en línea], 2012[Consulta: 10 junio 2017]. Disponible en: http://www.bajatec.net/energia-produccion-conservacionalmacenaje/briquetas-de-biomasa-caseras-ii

GANDUGLIA, Federico, \& et al. Manual de Biocombustibles. Lima-Perú: ARPEL IICA, 2009. pp.24-25.

FONSECA CUENCA Edison Geovanny; TIERRA TINGO Luis Fernando. Desarrollo de un proceso tecnológico para la obtención de briquetas de aserrín de madera y cascarilla de arroz, y pruebas de producción de gas pobre. (Trabajo de titulación) (Ingeniero) Escuela Superior Politécnica de Chimborazo, Riobamba-Ecuador. 1998.pp. 3467 [Consulta: 2017-05-23]. Disponible en: dspace.espoch.edu.ec/bitstream/123456789/402/1/12T00809.pdf

DE LUCAS, Ana; \& et al. Biomasa, Biocombustibles y Sostenibilidad. Madrid-España: ITAGRA.CT, 2012. pp. 21-31-34.

SOUSA.J, CABRAL DE, et al. Produção de briquetes e péletes a partir de resíduos agrícolas, agroindustriais e florestais. Brasília: Embrapa, 2012. pp. 82-90. ISSN 2177-4439. 